\title{
ICT Paradox: Cost Efficiency of Web Based Learning
}

\author{
Tety Elida \\ Gunadarma University, Jakarta, Indonesia
}

\begin{abstract}
Indonesia government in this term Directorate General of Higher Education providing grants for ICT infrastructures supplied through all bequest competitions. The kinds and amount of the grants are various which can be used to provide hardware to make ICT based teaching materials. The government issued a huge amount of funds, therefore, it must be balanced with an optimal utilization. This research aims to analyze cost efficiency of dual mode web-based learning in Indonesia. The object of this research is four higher educations in Indonesia. The analysis is done by comparing the average cost per student and the average cost per subject among 4 institutions. The result showed that there are institutions that issued higher cost compared with the others in producing the same learning media.
\end{abstract}

Keywords: cost efficiency, cost of learning, ICT paradox

\section{Introduction}

Nowadays, web based learning becomes the alternative option of learning model, especially in university level that has a lot of students. Such learning model enables them to perform the whole course with a large number of students and employs only one facilitator. University management no longer provides parallel classes and facilitators (lecturers) in a certain number appropriate with number of students. Web based learning will cause an efficient image compared with the conventional learning as a result of the lack of class construct budget and the decrease of salary expenditures for the facilitators.

The utilization of ICT in Indonesia is still less compared with other countries such as Malaysia, Thailand and Singapore (Dutta \& Mia, 2009). To enhance the uses of ICT in education, the Indonesian government, through Presidential Decree Number 20 of 2006, established "Dewan Teknologi Informasi dan Komunikasi Nasional" (DeTIKNas) which is responsible to formulate general policy and strategic directing of national development through efficiency of technology and information. The first pillar of national development strategy of ICT is the infrastructures of telecommunication which supplies cheaply and inclusively.

Infrastructure supplying sector is hoped to increase the quality of teaching all over Indonesia. In the next few years, ICT is expected to be a media of education in all formal and informal education level in Indonesian (Rusli, 2006). One of the successful infrastructure established by the National Education Department in collaboration with other related institutions is internet network called JARDIKNAS. Particularly, for higher educators, both state and private college is developed the system and college information network planned step by step which will connect the entire college in Indonesia called Indonesian Higher Education Network (INHERENT).

Tety Elida, Ph.D., Economics Research Institution, Gunadarma University. 
Through INHERENT program, the government, in this term Directorate General of Higher Education, provides funds for ICT infrastructures. Kinds and amount of bequest are various which can be used to provide hardware until the making of ICT based teaching materials. After the end of bequest period of higher education that get the bequest during certain time, in the next years, it is hoped that they can develop independently the use of ICT in learning. It means that there is certain budget required to be provided by management institution for directing the ICT based learning.

Based on INHERENT grants, it is known that the government spent a large amount of costs for the development of web-based learning. It should be followed by an efficient allocation on cost and an optimal use. Optimal use of the web can be identified by looking at the size of the web. Therefore, this research wanted to know the cost efficiency and analyze the use of the web as a measure of productivity.

\section{Cost Efficiency of Web Based Learning}

Using communication technology, web-base learning will effect the changing in cost of educational implementation. Intuitively, no need of classroom, the decrease staff of facilitator and subject media that can be used together, will affect the cost of implementation of web based learning to be lower than conventional learning. Hulsmann (2004) stated that the cost of web based education with large number of students will decrease the unit cost. However, using communication system will not be cost-effective, because the increase of students also need to increase the web server and internet access capacities.

Rumble (1999) stated that to answer whether long distance learning system is an inexpensive alternative learning system it depends on the number of students involved, the sophisticated media is used, the availability of face to face facility that prepared and depends on whom it will be charged upon the cases above. Research of Rumble (1999) pointed out that online learning and open education in many countries have not been efficient yet. In several countries, when calculating the average cost, for each student, in long distance learning system or open education costs are higher than the conventional education system.

Bayrak and Kesim (2005) studied on a cost analysis on online learning in University of Anadolu in Turkey, by calculating the cost per student, the cost per credit unit and the cost per subject. These three costs are cheaper compared with the conventional learning. Besides, the total income on online learning during two year observation and prediction for next three years, are bigger than online learning. So, it can be concluded that the investment in online learning is profitable. Besides, using online learning method is more effective in terms of time than the conventional learning.

Different result is gained by Ramage (2005), 83\% of 12 online high educational institutions in Illinois is not efficient and resulting a negative value of return on investment (ROI). This finding is not consistent with other researches, but it can be explained by the statement of Rumble (1999), that the cost on online learning implementation are various and influenced by various factors.

\section{Method}

The objects of this research are four universities in Indonesia that conduct a web-based learning in a dual mode. The data were collected after a year when the grant program was finished. The data used are the size of a web that include the number of pages, links and courses offered by web based learning. These data are obtained 
from Google search engine. While the costs of the learning are obtained from the questionnaires that were given to the learning center director.

The analysis is done by describing the use and the size of web, the allocation cost on each step of development of web based learning and comparing the average cost per student and average cost per subject among 4 institutions.

\section{Result and Discussion}

\section{The Use of Web Based Learning}

The use of web learning in the four institutions sample can be seen in Table 1. Institution A offers a web based learning in 70 departments. The average number of courses delivered virtually in every department is 10 courses. Implementation of virtual learning is governed by the rector's policy, which stated that on certain subjects, lecturers are required to submit a virtual material at least 2 times in one semester. During the last year, it is known that an average virtual delivery course is 5 times per subject. The number of meetings are 14 times in one semester.

Table 1

The Use of Web Learning on the Institution

\begin{tabular}{lrrrr}
\hline & \multicolumn{3}{c}{ Higher education } \\
\cline { 2 - 5 } & A & B & C & D \\
\hline Number of department & 70 & 1 & 2 & 18 \\
Number of courses in each department & 10 & 2 & 15 & 16 \\
Number of virtual delivery in each subject & 5 & 5 & 2 & 3 \\
Number of lectures & 2 & 2 & 1 & 2 \\
Number of students & 20 & 30 & 50 & 40 \\
\hline
\end{tabular}

Institution B received grants in 2007. These grants are used entirely for the development of ICT facilities, including the provision of audio-video conference, as a means of communication with other institutions. The web-based learning implements only in one department, and the numbers of courses delivered virtually are 2 courses.

Institution $\mathrm{C}$ also used the grant to enhance institutional capacity in the INHERENT network infrastructure. Web learning is used for assigning quiz or test in 2 departments, and implemented in 15 courses. The use of web based learning is still limited.

Institution D used the grant to increase the accessibility and network connectivity, and strengthen the development of ICT based learning materials. Web based learning carried out in all 18 departments and average number of delivered course in each department is 16. The number of virtual delivery in each subjects are 3 times. This activity is regulated by the institution based on the rector's policy.

Implementation of web-based learning in the institution $B$ and institution $C$ is less appreciated by the lecture. Lecture time spend on delivery virtual material tends to be longer than the time required in a conventional learning. It contradicts with Bayrak and Kesim (2005) that states using online learning method is more timesaving than the conventional learning. This amount of time, possibly will cause less motivated lecturers to use the web based learning. On the other hand, their compensation payments are equal to the conventional 
learning. Other factors that cause this low usage are due to the lecture skills in the use of ICT and pedagogical skills to make a virtual material are limited.

To solve these problems, for example, institution A issued a bandwidth incentive policy to improve teacher motivation in delivering learning materials through a web. Besides, in order to improve teaching abilities, institution A and D always held a periodic training on the use of ICT skills and improved the teacher ability to design interactive materials.

\section{Web Learning Size}

Total numbers of web pages on the 4 institutions vary widely. The number of web page of Institution $A$ is the largest with 93,400 pages. This can be understood when linked to the provision of virtual material performed on 70 departments. Based on Table 2, it can be seen that the number of web pages increased when the number of virtual courses offered increased.

Table 2

Size of Web Learning on the Sample Institution

\begin{tabular}{lrrrr}
\hline & \multicolumn{4}{c}{ Higher education } \\
\cline { 2 - 5 } & \multicolumn{1}{c}{ A } & B & C & D \\
\hline Number of web pages & 93,400 & 572 & 1,870 & 8,920 \\
Number of links & 2,179 & 115 & 310 & 3,486 \\
\hline
\end{tabular}

Note. Source: Google search engine, accessed on January 13, 2010.

The number of link provided that refers to the web learning materials was also different. The number of links provided by Institution D is the largest when compared with the three other institutions. Links are provided to refer to teaching materials that are available on the sites and files outside the site.

\section{Cost of Web Based Learning}

The cost of web-based learning in each college varies greatly. The highest cost recorded is 7 billions rupiah and the lowest is 65 million rupiah. Costs are allocated on need analysis phase, design phase, the web development stage, implementation stages and evaluation phase. The cost allocations of web based learning at each stage are listed in Table 3.

Table 3

The Cost Allocation of Developing Web Based Learning

\begin{tabular}{lllll}
\hline \multirow{2}{*}{ Activity } & \multicolumn{4}{c}{ Cost } \\
\cline { 2 - 5 } & $\mathrm{A}$ & $\mathrm{B}$ & $\mathrm{C}$ & $\mathrm{D}$ \\
\hline Need analysis & $10 \%-20 \%$ & $30 \%-40 \%$ & $10 \%-20 \%$ & $0 \%-10 \%$ \\
Teaching materials design & $30 \%-40 \%$ & $20 \%-30 \%$ & $20 \%-30 \%$ & $20 \%-30 \%$ \\
Web development & $10 \%-20 \%$ & $30 \%-40 \%$ & $40 \%-50 \%$ & $30 \%-40 \%$ \\
Implementation & $10 \%-20 \%$ & $10 \%-20 \%$ & $10 \%-20 \%$ & $10 \%-20 \%$ \\
Evaluation & $10 \%-20 \%$ & $10 \%-20 \%$ & $0 \%-10 \%$ & $0 \%-10 \%$ \\
\hline Total cost per annum & 7 billions & 65 millions & 150 millions & 3 billions \\
\hline
\end{tabular}

The cost allocations on need analysis phase in the three institutions are the same, except in institution A. Allocation of $30 \%-40 \%$ for the needs analysis phase is too large when compared with Fairley (1985) which states 
that the distribution effort in the analysis phase of a software application is approximately $10 \%$. The cost allocation in teaching materials design at institution $\mathrm{A}$ is the highest when compared to the three other institutions. It is because the institution concerns about developing learning materials. After period of the grant, this institution developed interactive teaching material such as video streaming.

The allocation value that looks big enough when compared among the four institutions is a web development costs in institution C. At this stage, the highest cost was triggered by honorariums programmers and software license costs. Rumble (2001) suggested these costs can be minimized by the choice of free software. The smallest cost is allocated to the evaluation stage. According to the activities carried out at this stage, the portion of the cost allocation is reasonable, and their values at the four institutions are not different.

The average learning costs for each student and each subject in the four institutions are very different. The average cost less, with the increasing number and the number of users and courses, as shown in Table 4. It appropriates with Rosenberg (2001), UNESCO (2002), and Rumble (2003) state that several factors influence a web-based learning are the number of students and the number of courses. On the other hand Hülsmann (2004) states that the increase in the number of students can also lead to increase costs of technology, such as the amount of a particular student network access capacity should be increased. From the four institutions, it is showed that the cost of the internet will be greater in line with the increase of users and usage.

Table 4

The Cost of Web Based Learning

\begin{tabular}{llccc}
\hline \multirow{2}{*}{ Cost (rupiahs) } & \multicolumn{4}{c}{ Higher education } \\
\cline { 2 - 5 } & $\mathrm{A}$ & $\mathrm{B}$ & $\mathrm{C}$ & $\mathrm{D}$ \\
\hline Total cost per annum & 7 billions & 65 millions & 150 millions & 3 billions \\
Internet cost per month & 700 millions & 15 milions & 30 millions & 400 millions \\
Users per annum & 28,000 & 120 & 1000 & 23,040 \\
Courses per annum & 1,400 & 4 & 20 & 576 \\
Average cost per student & 250,000 & 541,667 & 150,000 & 130,208 \\
Average cost per course & $5,000,000$ & $16,250,000$ & $7,500,000$ & $5,208,333$ \\
\hline
\end{tabular}

Institution A has the largest cost of web-based learning out of the 4 institutions, but the average cost of learning per subject and the average cost per student is relatively small compared with three other institutions. These small costs are due to the number of students, and the number of courses that offered by the institution. In contrast to the institution B, although the costs incurred for the implementation of a web-based learning is smaller than the others, but the average cost per student and the average cost per subject are the greatest. These great values are due to the number of students and the number of courses that offered by the institution.

\section{Conclusions}

Based on the average cost per subject and the average cost per student, the institution A and institution D are more efficient compared with two other institutions. The average cost per student in institutions $C$ is the lowest one among the 4 institutions. This value is not the real cost of web based learning, because the web is used only for delivering a course assignment. 
Viewed from the condition of the 4 institutions, the use of ICT in learning should be followed by policy support from the institutions. The policies should be in the form compensation payments and develop a periodical training for the lectures. Although empirical studies stated that ICT-based learning is more efficient than conventional learning, in Indonesia based on 4 institutions sample, but this model is still not efficient because of its less utilization.

\section{References}

Bayrak, C., \& Kesim, E. (2005). An evaluation with respect to e-learning and economic analysis of the graduate program offered in Anadolu University's Institute of Educational Sciences. Turkish Online Journal of Distance Education, 6(1), 1-9.

Dutta, S., \& Mia, I. (2009, April). The global information technology report 2008-2009: The networked readiness index ranking. World Economic Forum. Retrieved from www.weforum.org

Fairley, R. (1985). Software engineering concepts. Singapore: McGraw-Hill.

Hulsmann, T. (2004). Low cost distance education strategies: The use of appropriate information and communication technologies. International Review of Research in Open and Distance Learning, 5(1), 1-14.

Ramage, T. (2005). A system level comparison of cost-efficiency and return on invesment related to online course delivery. Journal of Instructional Science and Technology, 8(1), 1-20.

Rosenberg, M. J. (2001). E-learning. New York: McGraw-Hill.

Rumble, G. (1999). Technology, distance education and cost. Journal of Education and Development in the Caribbean, 3(2), 1-25.

Rumble, G. (2001). The cost and costing of networked learning. Journal of Asynchronous Learning Networks, 5(2), 75-96.

Rumble, G. (2003). Modeling the cost and economics of distance education: Handbook of distance education. New Jersey: Lawrence Erlbaum Associates.

Rusli, A. (2006, December 12). National policy for administrative reform information and communication technology, National Seminar on Utilization of Information and Communication Technology in the National Education, Ministry of Education, Jakarta.

UNESCO. (2002). Open and distance learning: Trends, policy and strategy considerations. France: Division of Higher Education. 